\title{
Da dura tarefa de tornar-se mulher
}

\author{
Simone Pereira Schmidt \\ Universidade Federal de Santa Catarina
}

Resumo: 0 artigo põe em diálogo o conto "O baile de Celina" (1950), publicado na Antologia de Contos (2012) da escritora moçambicana Lília Momplé, e o filme de curta-metragem Phatyma (2010), resultante da parceria entre o cineasta Luiz Chaves e a romancista Paulina Chiziane. Através dessa leitura, pretendo discutir as tensões resultantes da complexa intersecção gênero/raça que se faz presente na experiência de meninas e mulheres moçambicanas, em situações que se estendem desde o colonialismo até os dias de hoje. Tomando como ponto de partida para minha abordagem o tema da formação das mulheres, pretendo retomar as reflexões de Simone de Beauvoir em sua célebre proposição sobre o tornar-se mulher. Minha leitura do conto e do filme parte, portanto, da leitura de Beauvoir - ou, de forma mais exata, da primeira parte do volume 2 de o segundo sexo, a qual se intitula, precisamente, Formação. Colocando em contato - e em atrito - o texto da filósofa francesa, que nos fornece pressupostos sobre os quais desenvolvemos a crítica feminista nos séculos XX e XXI, e os textos literário e cinematográfico de Lília Momplé e Paulina Chiziane/Luiz Chaves, pretendo abordar algumas discussões sobre a formação escolar e afetiva das mulheres moçambicanas, situadas no tenso espaço de negociação (ou conflito) entre "tradição" e "modernidade", família e escola, subalternidade e resistência, meio rural e urbano, infância e idade adulta - apenas para citar alguns dos muitos temas que se fazem presentes em ambas as narrativas.

Palavras-chave: ficção moçambicana contemporânea, colonialismo, colonialidade, gênero, raça

Abstract: This article establishes a dialogue between the short story "O baile de Celina" (1950), by the Mozambican writer Lília Momplé, and the short film Phatyma (2010), resulting from the partnership between the filmmaker Luiz Chaves and the novelist Paulina Chiziane. Through this comparative reading, I intend to 
discuss the tensions that result from the complex intersection between gender and race in the experience of Mozambican women, in situations that extend themselves from colonialism to present days. Taking as a starting point the reflections of Simone de Beauvoir in her famous proposition about "becoming a woman", the focus will be on the literary and cinematic texts of Lília Momplé and Paulina Chiziane / Luiz Chaves, in order to address some debates about women formation in Mozambique, in the tense space of negotiation between "tradition" and "modernity", family and school, subordination and resistance, rural and urban, childhood and adulthood - just to name a few of the many themes that are present in both narratives.

Keywords: Mozambican contemporary fiction, colonialism, coloniality, gender, race

A célebre frase de Simone de Beauvoir, "Ninguém nasce mulher; torna-se mulher" se consagrou como um ícone do pensamento feminista, à medida que o impacto da obra da pensadora francesa foi crescendo através do século XX. Após sucessivas gerações de teóricas que se dedicaram a reexaminar suas formulações, esta frase-ícone chega à segunda década do século XXI perfeitamente revigorada, com a força dos estudos de gênero e a revisitação de autoras do porte de Judith Butler. Ocorre que nesta frase-valise se encontra potencialmente o que de mais significativo se discutiu sobre as complexas imbricações entre sexo, corpo, identidade e gênero. Segundo Beauvoir, 'tornar-se mulher' implica, conforme a leitura de Butler, assumir e traduzir um conjunto de prescrições historicamente impressas neste locus de interpretações que é seu corpo. Colocando em relação dialética cultura e eleição, normas impostas e projeto subjetivo, a pensadora francesa propõe que “'existir' o próprio corpo se converte em uma forma pessoal de assumir e reinterpretar as normas de gênero recebidas" (Butler s.d [1987]: 142). ${ }^{1}$ Assim, sem descartar a ideia de uma subjetividade que deseja e se constrói, Beauvoir destaca que a identidade social da mulher adulta atravessa um longo processo de formação em que 'tornar-se mulher' lhe será ensinado em pequenas e grandes lições diárias. Seu estar no mundo, a partir de sua posição de sujeito preso à corporalidade, seus projetos de vida e de destino, são minuciosamente desenhados pela família, pela escola, pela sociedade. "É uma estranha experiência", diz Beauvoir, 
(...) para um indivíduo que se sente como sujeito, autonomia, transcendência, como um absoluto, descobrir em si, a título de essência dada, a inferioridade: é uma estranha experiência para quem, para si, se arvora em Um, ser revelado a si mesmo como alteridade. É o que acontece à menina quando, fazendo o aprendizado do mundo, nele se percebe mulher. A esfera a que pertence é por todos os lados cercada, limitada, dominada pelo universo masculino; por mais alto que se eleve, por mais longe que se aventure, haverá sempre um teto acima de sua cabeça, muros que lhe barrarão o caminho. (Beauvoir 1980: 39)

Perceber o caráter construído do que se convencionou chamar 'mulher' na sociedade burguesa ocidental moderna implica apontar na direção de se compreender também, a partir de Beauvoir, a possibilidade de se desconstruir essa mesma formação. Butler conclui sua leitura de Beauvoir afirmando que “(...) as mulheres não têm nenhum tipo de essência e portanto (...) desde logo, o que chamamos uma essência ou um fato material simplesmente é uma opção cultural reiterada que se disfarçou de verdade natural" (Butler s.d [1987]: 154).

0 tema da formação feminina, primeiramente no seio da família, estendendo-se depois em outras instituições sociais, predominantemente na escola, é amplamente desenvolvido no segundo volume de $O$ segundo sexo, proporcionando-nos uma visão em profundidade das prescrições e dos constrangimentos a que são submetidas as mulheres desde seus primeiros anos de vida, como preparação minuciosa rumo ao seu destino único de mulheres burguesas. Na perspectiva de nosso olhar contemporâneo para o painel descrito por Beauvoir, nossa leitura ora se congratula na constatação das mudanças promovidas por décadas de luta feminista a partir dos 60-70 do século $\mathrm{XX}$, as quais nos permitem hoje nos distanciar do quadro sombrio que ensejou a reflexão da filósofa; ora, por outro lado, nossa leitura se inquieta ao se ver confrontada com a incômoda permanência de inúmeras situações analisadas em sua obra. Se a mulher hoje não se encontra condicionada ao destino único do casamento e da maternidade, por certo ainda sua experiência corpórea a constrange, confina e ameaça, diante da falta de liberdade e do medo que enfrenta no desafio à sua autonomia.

E o que dizer, então, de outros deslocamentos possíveis, que podemos efetuar a 
partir da discussão do 'tornar-se mulher' beauvoiriano? Se olharmos para além das fronteiras temporais, buscando os deslocamentos traçados também no espaço, examinando os percursos do que se convencionou chamar as geografias do poder? Pensando nesses deslocamentos, pretendo colocar em diálogo o conto "O baile de Celina" (1950), publicado na Antologia de Contos (2012) da escritora moçambicana Lília Momplé, e o filme de curtametragem Phatyma (2010), resultante da parceria entre o cineasta Luiz Chaves e a romancista Paulina Chiziane. Através dessa leitura, pretendo discutir as tensões resultantes da complexa intersecção gênero/raça que se faz presente na experiência de meninas e mulheres moçambicanas, em situações que se estendem desde o colonialismo até os dias de hoje. Tomando como ponto de partida para minha abordagem o tema da formação das mulheres, pretendo retomar as reflexões de Simone de Beauvoir em sua consagrada proposição sobre o "tornar-se mulher". Minha leitura do conto e do filme parte, portanto, da leitura de Beauvoir - ou, de forma mais exata, da primeira parte do volume 2 de $O$ segundo sexo, a qual se intitula, precisamente, "Formação". Colocando em contato - e em atrito - o texto da filósofa francesa e os textos literário e cinematográfico de Lília Momplé e Paulina Chiziane/Luiz Chaves, pretendo abordar algumas discussões sobre a formação afetiva e escolar das mulheres moçambicanas, situadas no tenso espaço de negociação (ou conflito) entre "tradição" e "modernidade", família e escola, subalternidade e resistência, infância e idade adulta - apenas para citar alguns dos muitos temas que se fazem presentes em ambas as narrativas.

Através do enredo de "O baile de Celina", nos reportamos ao Moçambique colonial, em período ainda uma década distante dos movimentos que vieram posteriormente abalar os alicerces do regime salazarista em África. Sobre a jovem protagonista recai todo o peso de uma sociedade ainda sólida em seus princípios coloniais, patriarcais e racistas. Marcada por uma história familiar em que o trauma da mestiçagem se impõe como uma fatalidade sendo fruto da relação entre um homem branco e uma mulher negra, que, seguindo os costumes da época, resultara em descaso e abandono -, a mãe de Celina empenha-se por oferecer à filha um outro destino, diferente do seu. Seu projeto para a filha é o estudo, como chave, senão de ascensão, ao menos de sobrevivência e afirmação social: “Estuda, filha! Só a 
instrução pode apagar a nossa cor. Quanto mais estudares, mais depressa serás gente!” (Momplé 2012: 54).

Aqui encontramos um curioso distanciamento entre as reflexões de Beauvoir sobre a formação da mulher e o caso de Celina. Beauvoir observa enfaticamente o quanto o destino da jovem mulher está irredutivelmente associado ao projeto matrimonial:

Admite-se unanimemente que a conquista de um marido (...) é para ela o mais importante dos empreendimentos. (...) Ela se libertará do lar paterno, do domínio materno e abrirá o futuro para si, não através de uma conquista ativa e sim entregando-se, passiva e dócil, nas mãos de um novo senhor. (Beauvoir 1980: 67)

No Moçambique colonial, essa mesma matriz se reproduz, mas restrita ao mundo dos brancos; é para o casamento com as moças das famílias portuguesas que se dirigem os homens, após as aventuras com as mulheres nativas. A estas, restava a resignação a um destino de abandono amoroso, ou o sonho da assimilação através do ingresso admitido no mundo dos brancos.

Convictas da inferioridade social marcada na cor de sua pele, a mãe de Celina e suas amigas comentam, no início da narrativa, a paixão desenfreada do Governador por "cavalos e mulatas bonitas". Era o costume. A lamentar, apenas a má sorte da esposa traída: "Tenho pena da mulher dele - critica D. Violante, franzindo os lábios - ainda se ele a enganasse com outras brancas, mas com mulheres de raça inferior, custa muito” (Momplé 2012: 55). Nessa breve cena vemos o modo como se entranhava na consciência dos colonizados, a partir do pressuposto da naturalização da desigualdade racial, a superioridade dos colonizadores. Para as 'mulatas', restava a condição de amantes provisórias e subalternas, não lhes cabendo desejar mais do que essa precária condição social e amorosa, já que o malogro do projeto de um casamento interrracial estava sempre colocado em seu horizonte. A mãe de Celina, dona Violante, era ela própria fruto de um casamento interrracial mal-sucedido. O pai português, atendendo aos conselhos dos amigos, achou por bem abandonar mulher e filha em busca de casamento proveitoso com mulher branca. Eis por que D. Violante investe em outro projeto para sua filha mestiça. Buscando garantir-lhe um destino diferente do seu 
e todas as mulheres de sua condição racial e social, busca por força introduzir a filha no mundo dos brancos através da educação escolar. Assim nos descreve a narradora as motivações da personagem, desde sua infância, quando sofre o abandono paterno:

Violante contava nessa altura oito anos. Mas já experimentava, à sua medida, a insegurança, os medos, as violentas contradições inerentes à sua condição de mulata colonizada. E o sofrimento que tal condição lhe causava foi-se tornando quase insuportável com o decorrer dos anos. Por isso, quando nasceu Celina, sua única filha, jurou a sim mesma defendê-la, a todo custo, das humilhações que lhe estariam reservadas pelo único facto de ser mulher. E procurou cumprir tal juramento, adoptando uma estratégia que lhe pareceu mais adequada aos seus intentos. Na realidade, tal estratégia resumia-se em proporcionar à filha o máximo de instrução pois, a seu ver, este era o único meio de lhe garantir um mínimo de aceitação por parte dos senhores da terra, ou seja, os colonos. Donde lhe vinha tamanha convicção, nem ela própria sabia. Talvez do facto de não conhecer um só mulato com nível de instrução superior ao primário. (idem: 52)

A ação narrada no conto situa-se no dia da formatura de Celina, quando se dão os preparativos para o baile onde os formandos do Liceu celebrarão o evento. Trata-se de um dos acontecimentos sociais mais importantes da colônia. O Liceu Salazar (e o nome da instituição é digno de nota) é um dos mais importantes estabelecimentos de Moçambique, razão pela qual D. Violante dedicou sua vida, suas noites de costureira e todo seu esforço para que a filha pudesse lá estudar. 0 momento presente é para ela o coroamento de anos de sacrifício familiar. As amigas comentam, corroborando a sua satisfação íntima: " - O que faz a instrução! Quando é que a Violante sonhou algum dia ir ao baile do Liceu Salazar! Mas como a filha conseguiu..." (idem: 54).

Ocorre, entretanto, que, destinado aos filhos das melhores famílias colonialistas, o Liceu Salazar não costuma acolher pessoas 'de cor'. Em persistente desconforto, Celina atravessou os anos do Liceu em 'desassossego de alma', como nos diz a narradora. "No 7o ano, Celina e um jovem indiano são os únicos alunos de cor, e em todo o Liceu não existe um só aluno negro. Durante os primeiros anos, em tal ambiente, Celina só desejava passar despercebida" (idem: 53). No dia de sua formatura, enquanto a mãe exibe às amigas o vestido de baile confeccionado por suas mãos para a filha, Celina enfrenta o mais dramático 
episódio de seu doloroso convívio forçado com o mundo dos brancos. Chamados à sala do reitor às vésperas do evento da formatura, ela e seu colega indiano, únicos diferentes aceitos no seio da nata colonialista, são informados secamente que não poderão comparecer ao baile:

- Sem dúvida que vocês compreendem ... (...) Há certas coisas que é preciso dar tempo ao tempo. Vem o senhor Governador-Geral e pessoas que não estão habituadas a conviver com gente de cor. E vocês também não haviam de sentir-se à vontade no meio delas! Para evitar aborrecimentos de parte a parte, achamos melhor vocês não irem ao baile. (idem: 57)

Em choque, Celina perambula pelas ruas de Lourenço Marques sem coragem de voltar para casa e dar a notícia aos pais. Quando enfim retorna, seus gestos silenciosos são mais eloquentes do que qualquer palavra de revolta. A sós em seu quarto, ela corta seu vestido de baile, branco como o sonho de sua mãe, "em pequeninos pedaços que se espalham pelo chão como frágeis e vaporosas nuvens, desfeitas pelo vento" (idem: 58).

Sessenta anos, uma independência e duas guerras separam a trágica condição de Celina dos impasses vividos pela menina Phatyma, protagonista do filme de curtametragem que tem seu nome como título, lançado em 2010, dirigido por Luiz Chaves, com texto do diretor em coautoria com Paulina Chiziane.

Phatyma é ambientado no sul de Moçambique, e nos apresenta os primeiros anos de vida da menina, em seu ambiente familiar e escolar. Narrado em primeira pessoa, nas cenas iniciais vemos, em flashback, alguns breves episódios celebrando o nascimento da menina Phaty, enquanto sua voz, em off, explica o significado de seu nome, um nome de sorte, que significa 'brilho'. Os créditos de abertura nos surgem sobre uma cena de alegria e leveza: música ritmada e envolvente, e a menina dançando livre, sorridente, num caminho de terra que nos sugere um ambiente rural.

Logo após a primeira sequência, o que se segue é uma cena no ambiente doméstico, uma casa muito simples, onde se veem mulheres trabalhando e um homem que aparece e desaparece rapidamente da cena, seguido de um menino que faz o mesmo, enquanto a voz da personagem narra em off: 
Eu vivo no sul de Moçambique. Estou sempre ao lado da minha mãe e da minha avó. Meu pai está sempre a trabalhar longe de casa. Quando não está na África do Sul, está a cuidar do gado, e só o vejo aos fins de semana. Os meus irmãos seguem o mesmo caminho. A mim foi ensinado que tenho que ficar em casa. A minha mãe e minha avó é que me dão lições de como ser mulher e co mo ser homem. ${ }^{2}$

Nas palavras da narradora e na cena apresentada podemos ler a formação da menina como aprendizado de trabalho incessante e desigual, e como preservação de uma ordem previamente traçada e imutável. A cena seguinte corrobora essa ideia, ao apresentar as figuras femininas da família a se moverem, silenciosas e sérias, entre os panos da tradição moçambicana estendidos no varal, enquanto a voz da menina nos diz: "Sinto que posso tornar-me a minha mãe, que também deve ter tido sonhos, e tornou-se a minha avó, que mesmo que sonhasse, tornou-se alguém que já existiu antes dela, e não perguntou o que ela gostaria de ser quando crescesse" (Phatyma).

São visíveis aqui as semelhanças com o texto de Beauvoir, no que diz respeito aos aspectos centrais da formação das meninas e adolescentes, o que nos leva a pensar nos modos como diferentes patriarcalismos se intersectam no que diz respeito à sua educação voltada ao aprendizado da submissão.

A revolta é tanto mais violenta quanto mais vezes a mãe perdeu o prestígio. Ela se apresenta como a que espera, suporta, se queixa, chora, faz cenas: e, na realidade quotidiana, esse papel ingrato não conduz a nenhuma apoteose (...). Seu destino aparece como protótipo da insossa repetição: por ela a vida apenas se repete estupidamente sem levar a lugar algum. Presa a seu papel de dona de casa, ela detém a expansão da existência, é obstáculo e negação. A filha não quer assemelhar-se a ela e rende culto ás mulheres que escaparam à servidão feminina: atrizes, escritoras, professoras. (Beauvoir 1980: 36-37)

Como que ainda a ecoar as palavras de Beauvoir, a cena seguinte do filme mostra a menina de joelhos, imperiosamente submetida aos ditames familiares, que lhe apontam a obediência aos homens da casa como primeiro mandamento:

Em casa ensinam-me que, diante de um homem, é preciso ajoelhar. Mesmo que ele seja criança; basta ser homem. Aprendi que é por respeito, mas assim, alguns homens pensam que são maiores, só por 
serem homens. Quem tem poder, pode querer e não querer. (Phatyma)

Enquanto ouvimos essas suas frases, a cena se torna mais escura, assumindo tons e contornos que sugerem violência. Diante da menina ajoelhada, projeta-se a sombra de um homem, e também contra ela avança uma mão ameaçadora, a sugerir que o espaço da casa pode ser um lugar de perigos e de violência, onde seu corpo e mesmo sua infância não se encontram em segurança. A imagem de Phaty então se ergue e se desdobra: enquanto uma imagem da garota permanece de joelhos, a outra se põe de pé, e a duplicação de sua figura, ora de joelhos ora erguida, nos diz de seus embates subjetivos diante daquilo que Beauvoir considerou o grande impasse colocado para as mulheres a partir de sua formação: de um lado, sua vocação para a liberdade, confrontada, por outro lado, com o aprendizado da alteridade, do imperativo de não se constituir em "um”, do ser forçosamente o 'outro' para si e para o mundo. Ao fundo de sua figura desdobrada, a voz da menina enuncia: "Alguns homens pensam que ser mulher, desde menina, é ser qualquer, ou até mesmo não ser, não ter, nem sequer se pertencer" (Phatyma).

Para Phaty, contudo, a escola vai desempenhar um papel fundamental de rompimento com os imperativos da tradição familiar. Contrariamente a Celina, para quem o Liceu e sua promessa de assimilação ao mundo dos brancos constitui uma penosa experiência de exclusão, para a pequena Phaty a escola será um lugar para aprender e estar entre iguais. A narradora explica que seu pai a deixou frequentar o colégio aos seis anos, por imposição do régulo de sua região e com apoio de algumas "senhoras das organizações". O filme a seguir nos mostra uma cena descontraída e marcada pela alegria, onde a protagonista brinca com as colegas no ambiente escolar. A partir dessa cena, ela narra o episódio que será o clímax do conflito, descortinando as tensões entre família e escola, aspecto crucial na formação de Phathy, que nos conduz ao desfecho da narrativa. Na cena há pouco apontada, a menina brinca com as amigas e se aventura num primeiro ingênuo namorico de colégio. Enquanto isso, sua voz ao fundo nos conta: "Gostei também daquela aula, quando disseram que os rapazes e raparigas têm os mesmos direitos. Fiquei mais contente. Corri pra dar esta notícia à minha mãe. Esperava que ela também ficasse 
satisfeita, mas aconteceu o contrário" (Phatyma).

Na sequência, as figuras femininas da mãe e da avó, se embatem, num cenário de sombras, contra a imagem da menina, protestando, em uma língua nativa do sul de Moçambique, contra a sua novidade:

Você, Phaty. Se o homem lavar a louça, qual será o trabalho das mulheres, hã? (...) Tens é que cuidar do teu marido. Ouvir tudo o que teu marido disser. Isso que andas dizer, onde ouviste? Isso só funciona na escola, lá onde ouviste. Aqui em casa isso não vai funcionar! (Phatyma)

O que salta aos olhos na cena é a visível disjunção que eclode entre os projetos familiar e escolar na formação de Phaty. Assim como para Celina, só que por razões diversas. Se para Celina, o projeto de aceitação social passava, segundo o desejo de sua mãe, pela escolarização e esse desejo se vê barrado pela própria escola, para Phaty se dá o contrário: é a escola que lhe descortina a possibilidade de reinvenção do sombrio destino que lhe aponta sua família, o que provoca o conflito entre as duas instituições, causando dor e revolta na menina. 0 grande impasse que se coloca para Phaty nesse momento é como conciliar duas verdades tão contraditórias. Onde estaria a verdade, na tradição familiar que a constituiu ou na escola que lhe oferecia um outro destino? Confusa, Phaty reage às palavras da mãe, e sua resposta e revolta nos apontam um passo para adiante, para além da tradição e da imutabilidade do seu destino:

Mas então porque que vocês me mandam à escola, se não concordam com o que nos vão lá ensinar? E por que que a escola não conversa com vocês pra evitar este tipo de confusão? Onde está o erro: na cultura ou na falta de diálogo entre as culturas? Mas eu sei que posso mudar. É minha hora de mudar. Posso ser moderna sem negar minhas tradições, pois só quero preparar o meu presente e aprender com o passado, e não tenho medo de ser diferente. (Phatyma)

Vemos, assim, que as duas narrativas dialogam no que diz respeito à disjunção entre o projeto familiar e o projeto escolar, os dois pilares da formação feminina. Na perspectiva de Beauvoir, esses dois pilares solidamente se complementam: "São as delícias da 
passividade que pais e educadores, livros e mitos, mulheres e homens, fazem brilhar aos olhos da menina" (Beauvoir 1980: 39).

Ao observarmos a disjunção família-escola, oposta ao quadro apresentado por Beauvoir, encontramos, nas duas narrativas, um importante deslocamento no que diz respeito à formação da mulher colonizada em relação à formação da mulher europeia. Em ambas, será preciso fazer interagir o gênero com temas derivados do colonialismo e da colonialidade, ou seja, intersectar necessariamente o gênero com raça, etnia e nacionalidade.

Nisso os dois relatos dialogam, cada um a seu modo, abordando os conflitos advindos da disjunção entre os projetos da família e da escola. Se a narrativa de Celina se encerra no trágico veto ao seu crescimento como sujeito e como identidade social, não sabemos qual terá sido seu destino... afinal, muitos dos intelectuais africanos viveram na diáspora essa sua mesma condição, e dessa condição diaspórica, exilada e partida nasceram os pensamentos e a ação libertários que vieram desembocar, anos mais tarde, nas lutas pela independência de seus países. ${ }^{3}$

Phaty, por sua vez, consegue enunciar ainda menina os paradoxos de sua formação, e delineia para si o projeto de síntese entre duas forças aparentemente irreconciliáveis: da tradição e da modernidade, da família e da escola, das culturas africanas e do conhecimento ocidental. A cena final nos mostra novamente a menina alegre e radiante no mesmo cenário dos créditos iniciais: a estrada de terra, a sugerir movimento e liberdade. Sua voz, confiante, nos acena com a esperança de dias melhores para as mulheres:

Fui um presente ao nascer, e meu futuro depende da força da mulher que sou; depende das decisões que eu tomar pra mim. 0 meu futuro é ser preciosa e protegida por aqueles que amo, assim como pela força da lua, que brilha na noite escura, ao refletir a minha luz. Chamo-me Phaty. (Phatyma)

O tom otimista das palavras da personagem, que concluem o curta-metragem logo a seguir aos embates entre o ponto de vista das mulheres de sua família, agarradas às tradições, e a defesa feita pela menina, de seu direito à educação e a um futuro melhor em termos de equidade de gênero, provoca-nos a reflexão em torno dos impasses entre o 
respeito às tradições culturais e o imperativo de mudanças, no que tange aos direitos das mulheres. Esta é sem dúvida uma discussão muito interessante, a ser levada adiante, especialmente, neste caso, pelas mulheres moçambicanas.

Sem pretender incorrer no equívoco já apontado por tantas feministas pós-coloniais, e primorosamente resumido na máxima que norteia a clássica reflexão de Gayatri Spivak sobre o tema - "homens brancos estão salvando mulheres de pele escura de homens de pele escura" (Spivak 2010: 91) -, evoco a proposição menos complexa, mas igualmente contundente, de Chimamanda Ngozi Adichie: "A cultura não faz as pessoas. As pessoas fazem a cultura. Se uma humanidade inteira de mulheres não faz parte da nossa cultura, então temos que mudar nossa cultura” (Adichie 2015: 45). 0 que fazer desta delicada tensão, sem reproduzir pressupostos que reafirmam a "modernidade" do Ocidente em torno de conceitos como os de 'civilização' e de cidadania, e sem incorrer na imposição de valores ocidentais, em mais um episódio de confirmação da hegemonia etnocêntrica que reafirma a colonialidade do poder? Essa é, com certeza, matéria para profícua discussão entre as mulheres que habitam o Sul global. 


\section{NOTAS}

${ }^{1}$ Artigo originalmente publicado em 1982: "Variations on Sex and Gender: Beauvoir, Wittig and Foucault", University of Minnesota Press.

${ }^{2}$ Chaves, Luiz / Paulina Chiziane (2010), Phatyma (filme de curta-metragem), Moçambique. As demais cenas do filme serão citadas com indicação apenas do título do filme de curta-metragem.

${ }^{3}$ Nos tempos do pós-guerra europeu, em meados dos anos 40, o senegalês Alioune Diop escreveu, a respeito de sua condição e a de seus companheiros, intelectuais imigrantes em Paris, na apresentação da então recém-fundada revista Présence Africaine:

Incapazes de voltar inteiramente às nossas tradições de origem ou de nos assimilar à Europa, tínhamos o sentimento de constituir uma raça nova, mentalmente mestiçada... Desenraizados? Éramo-lo, exactamente, na medida em que não tínhamos ainda pensado a nossa posição no Mundo e nos abandonávamos entre duas Sociedades, sem significado reconhecido nem numa nem noutra, a uma e a outra estrangeiros... (apud Neves 1974: 36)

Antecipando o que viria a ser conhecido como o entre-lugar, definido por Homi Bhabha (1998), da condição do sujeito pós-colonial, e também apontando algumas das características que definem a experiência em contraponto vivenciada pelo sujeito exilado, segundo Edward Said (2003), as palavras de Alioune Diop nos levam a compreender melhor o caráter dividido das subjetividades marcadas pelas experiências diaspóricas, determinada pelas relações coloniais, no período histórico anterior à libertação dos países colonizados. 


\section{Bibliografia}

Adichie, Chimamanda N. (2015), Sejamos todos feministas, São Paulo, Companhia das Letras. Bhabha, Homi K. (1998), O local da cultura, Belo Horizonte, Ed. UFMG.

Beauvoir, Simone de (1980), O segundo sexo, Rio de Janeiro, Nova Fronteira [4.ed., v.2].

Butler, Judith (1987), "Variações sobre sexo e gênero: Beauvoir, Wittig e Foucault", in Seyla Benhabib e Drucilla Cornell (orgs.), Feminismo como crítica da modernidade, Rio de Janeiro, Rosa dos Tempos, s.d., 139-154.

Chaves, Luiz / Paulina Chiziane (2010), Phatyma (filme de curta-metragem), Moçambique.

Momplé, Lília (2012) Antologia de contos, Moçambique, [s/ed.].

Neves, Fernando (1974), Negritude e revolução em Angola, Paris, Edições ETC.

Said, Edward (2003), "Reflexões sobre o exílio", in Reflexões sobre o exílio e outros ensaios, São Paulo, Companhia das Letras, 46-60.

Spivak, Gayatri C. (2010), Pode o subalterno falar?, Belo Horizonte, Editora UFMG.

Simone Pereira Schmidt é Doutora em Teoria Literária pela Pontifícia Universidade Católica do Rio Grande do Sul e Pós-Doutora em Literaturas de Língua Portuguesa pela Universidade Nova de Lisboa (2005) e em Literaturas Africanas de Língua Portuguesa pela Universidade Federal Fluminense (2012). Professora Associada da Universidade Federal de Santa Catarina (UFSC), é vinculada ao Literatual/UFSC (Núcleo de Pesquisa em Literatura Atual - Estudos Feministas e Pós-Coloniais de Narrativas da Contemporaneidade), ao IEG/UFSC (Instituto de Estudos de Gênero), ao GT “A Mulher na Literatura” da ANPOLL e ao Grupo de Pesquisa “África, Brasil, Portugal; interlocuções literárias” (UFF-CNPq). Atua nas áreas de estudos feministas e pós-coloniais, desenvolvendo pesquisa sobre "Escritoras africanas e a construção de um pensamento ao Sul”. 